\title{
Dietary intake of branched-chain amino acids in relation to general and abdominal obesity
}

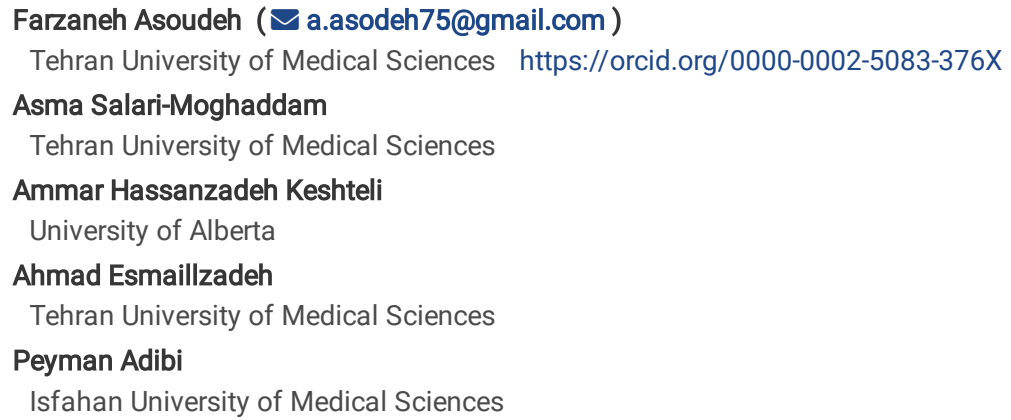

\section{Research Article}

Keywords: Branched-chain amino acids, BCAA, general obesity, abdominal obesity

Posted Date: April 26th, 2021

DOI: https://doi.org/10.21203/rs.3.rs-327173/v1

License: (c) (7) This work is licensed under a Creative Commons Attribution 4.0 International License. Read Full License

Version of Record: A version of this preprint was published at Eating and Weight Disorders - Studies on Anorexia, Bulimia and Obesity on July 15 th, 2021. See the published version at https://doi.org/10.1007/s40519-021-01266-6. 


\section{Abstract}

Purpose: Despite the huge evidence on the link between dietary protein intake and obesity, limited studies have examined the role of individual amino acids in this regard. This study aimed to investigate the association between dietary total and individual BCAAs intake and odds of general and abdominal obesity in a large group of adults.

Methods: This cross-sectional study was conducted among 8691 adults aged $18-55$ years in Isfahan, Iran. Dietary BCAAs were assessed using a validated dish-based 106-item semi-quantitative food frequency questionnaire (DS-FFQ). Information about weight and waist circumference were collected through a self-reported validated questionnaire. General obesity was defined as body mass index (BMI) $\geq 30 \mathrm{~kg} / \mathrm{m}^{2}$, and abdominal obesity was defined as waist circumference $(W C) \geq 88 \mathrm{~cm}$ for women and $\geq 102 \mathrm{~cm}$ for men.

Results: Mean age of study participants was $36.8 \pm 8.1$ years. Prevalence of general obesity was $9.2 \%$ in men and $9.7 \%$ in women and that of abdominal obesity was $13.3 \%$ and $36.2 \%$ in men and women, respectively. We found that participants in the top tertile of total BCAAs intake had higher odds of general obesity compared with those in the bottom tertile (OR: 1.42; 95\% Cl: 1.09-1.84). Such significant association was seen in men (OR: 1.57; $95 \%$ Cl: 1.05-2.34), but not in women (OR: $1.33 ; 95 \% \mathrm{Cl}: 0.94-1.89$ ) in our stratified analysis. We found no significant association between total BCAAs intake and odds of abdominal obesity. Stratified by sex, no significant association was observed between total BCAAs intake and odds of abdominal obesity [for men: (OR: 1.10; $95 \%$ Cl: 0.74-1.65) and for women: (OR: 1.08; $95 \% \mathrm{Cl}$ : 0.84-1.38)]. Assessing the association with individual BCAAs, a significant positive association was observed between dietary intake of valine (OR: 1.42; 95\% Cl: 1.10-1.84), leucine (OR: 1.43; 95\% Cl: 1.10-1.86), and isoleucine (OR: 1.42; 95\% Cl: 1.09-1.84) with general obesity. We observed no significant association between dietary intake of individual BCAAs intake and odds of abdominal obesity.

Conclusion: Dietary BCAAs intake was associated with an increased odds of general obesity, in particular among men. No significant association was observed between dietary BCAAs and abdominal obesity.

Level of evidence: Level V, descriptive cross-sectional study.

\section{Introduction}

Branched-chain amino acids are essential amino acids that are involved in protein synthesis, neurological function, and glucose metabolism (1). The role of these amino acids in cancer, cardiovascular disease and neurological disorders has been implicated (2). Several studies found that increased circulating BCAAs are associated obesity-related conditions such as metabolic disorders and type 2 diabetes (3-5). BCAAs and their metabolites can result in insulin resistance and impaired glucose tolerance and eventually increased visceral fat accumulation and obesity (6-8). Studies on the association of branched-chain amino acids and obesity are limited. Newgard et al. in a cross-sectional study showed that elevated serum concentrations of BCAAs are associated with obesity and obesity-associated insulin resistance in humans and animals (9). Another cross-sectional study demonstrated a positive relationship between BCAAs and visceral adipose tissue and insulin resistance. Some studies have revealed that dietary intake of BCAAs was associated with increased circulating levels of these amino acids (10). Lu et al. in a cross-sectional study investigated that increased BCAAs intake is associated with increased risk of insulin resistance and obesity in children (11). Conversely, dietary branched-chain amino acids have been associated with a lower prevalence of overweight and obesity in some other studies $(12,13)$.

Prevalence of obesity and central fat accumulation in Middle-Eastern countries is high. In addition, due to the high cost of protein sources, people in the Middle-East are more likely to eat eggs and legumes, which are cheaper and good sources of branched-chain amino acids. These amino acids may explain the increased prevalence of obesity and central fat accumulation in this region. However, the exact role of branched-chain amino acids in obesity and visceral fat accumulation is not clear. Given the limited evidence on the role of these amino acids in obesity this study aimed to investigate the relationship between dietary intake of BCAAs and odds of general and abdominal obesity in a large group of Iranian adults.

\section{Methods And Materials}

Participants: This cross-sectional investigation was done using the dataset of the Study on the Epidemiology of Psychological Alimentary Health and Nutrition (SEPAHAN), a project that investigated the prevalence and associates of functional gastrointestinal disorders (FGIDs). This study included a large group of Iranian adults working in 50 healthcare centers or doing administrative works in Isfahan University of Medical Sciences across Isfahan province. More information about the study, individuals took part, and methods used for data gathering were published previously (14). Required information about anthropometric measurements, socio-demographic characteristics, dietary intakes, and physical activity was collected using a self-administered questionnaire among 10,087 people aged 18-55 years at phase I of the study. Totally, 8691 subjects of these people returned the completed questionnaire (response rate $86.16 \%$ ) (14). In the current analysis, participants who had reported energy intakes outside of the range of $800-4200$ kcal were not included. Individuals with missing data about the outcome and covariate variables were not included in the study. Finally, we had a dataset of 6724 and 5219 subjects with complete data for the analysis on general and abdominal obesity, respectively (14). The study protocol was ethically approved by the Regional Bioethics Committee of Isfahan University of Medical Sciences.

Dietary assessment: We used a Willett-format 106-item Semi-Quantitative Food Frequency Questionnaire (DS-FFQ) to gather information about dietary intakes (15). This dish-based questionnaire was designed specifically for Iranian adults. Further information about design, food items, as well as validity of this FFQ has been reported elsewhere (16). This DS-FFQ contained five categories of foods: (1) carbohydrate-based foods; (2) dairy products; (3) vegetables and fruits; (4) mixed dishes; and (5) miscellaneous food items and beverages. We used a complete list of common foods and dishes that consumed by Iranian adults to develop the questionnaire. We asked subjects to report their dietary intakes of foods and mixed dishes based on multiple-choice frequency response categories varying from "never or less than once a month" to "12 or more times per day". Finally, the daily intake of all foods and dishes was estimated and converted into grams per day by household measurements (17). Daily intakes of nutrients for each participant were calculated using Nutritionist IV software

Page $2 / 10$ 
based on US Department of Agriculture's (USDA) national nutrient databank (18). Information about leucine, isoleucine and valine content of foods were extracted based on the USDA food composition table. Then, based on daily usual intake of foods containing these amino acids, we computed daily intake of these amino acids individually for each study participant. Total BCAAs were calculated by summing up the dietary intakes of leucine, isoleucine and valine.

Anthropometric assessment: Required information about anthropometric measures including height, weight and waist circumference (WC) were collected through a self-administered questionnaire. Body mass index (BMI) was calculated as weight in kilograms divided by the height in meters squared. Obesity was defined as having BMI $\geq 30 \mathrm{~kg} / \mathrm{m} 2$. Abdominal obesity was defined based on WC and NCEP-ATP III criteria (19). Participants were categorized into two groups based on their WC: normal ( $<88 \mathrm{~cm}$ for women and $<102 \mathrm{~cm}$ for men) and abdominal obesity ( $\geq 88 \mathrm{~cm}$ for women and $\geq 102 \mathrm{~cm}$ for men).

We assessed the validity of this questionnaire based on enrolment of 200 people from study participants from the same population. In that validation study, self-reported values of anthropometric indices were compared with actual measured values and we found that the correlation coefficients for self-reported weight, height and WC versus their corresponding measured values were $0.95(P<0.001), 0.83(P<0.001)$ and $0.60(P<0.001)$, respectively. The correlation coefficient for BMI that calculated from self-reported values and the one from measured values was $0.70(P<0.001)$.

Assessment of covariates: We collected information on age, sex, education (university graduate/under university graduate), marital status (married/single/divorced/widowed), family size ( $\leq 4 />4$ members), smoking status (non-smoker/former-smokers/current smokers), home ownership (owner/non-owner) and breakfast consumption (skippers/non-skippers) by using a previously tested self-administered questionnaire. Those who were eating breakfast $<4$ times/week were defined as breakfast skippers. Participants' physical activity levels were assessed using the General Practice Physical Activity Questionnaire (GPPAQ) (20) which is a simple four-level physical activity index reflecting a person's current physical activity. Participants were classified into four categories: active ( $>3 \mathrm{~h} /$ week), moderately active (1-3 h/week), moderately inactive ( $<1 \mathrm{~h} /$ week), and inactive (no physical activity). In the current analysis, we classified participants into two categories: $<1 \mathrm{~h} /$ week (physically inactive) or $\geq 1 \mathrm{~h} /$ week (physically active).

Statistical analysis: First, we classified participants according to the tertile cut-off points of BCAAs intake. General characteristics of study participants across tertiles of BCAAs intake were expressed as means \pm SDs for continuous variables and percentages for categorical variables. To examine the differences across tertiles, we used ANOVA for continuous variables and a chi-square test for categorical variables. Dietary intakes of study participants across tertiles of BCAAs intake were compared by using analysis of covariance (ANCOVA). We used binary logistic regression to estimate ORs and $95 \%$ Cls for the presence of general and abdominal obesity across tertiles of BCAAs intake in the crude and multivariable-adjusted models. In these analyses, age (continuous), sex (male/female), and total energy intake (continuous) were controlled for in the first model. Further adjustments were made for marital status

(married/single/divorced/widowed), physical activity ( $<1 \mathrm{~h} /$ week/ $\geq 1 \mathrm{~h} /$ week), smoking (non-smoker/former smokers/current smokers), family size ( $\leq 4 />4$ members), breakfast skipping (skippers/non-skippers), education (university graduate/under university graduate), and home ownership (owner/non-owner) in the second model. Dietary fiber intake was controlled for in the third model. P for trends was determined by considering tertiles of BCAAs intake as ordinal variables in the logistic regression analysis. All statistical analyses were done using the Statistical Package for Social Sciences (version 20 ; SPSS Inc.). P<0.05 was considered as statistically significant.

\section{Results}

Mean age of study participants was $36.8 \pm 8.08$ years. The prevalence of general obesity was $9.2 \%$ in men and $9.7 \%$ in women and that of abdominal obesity was $13.3 \%$ and $36.2 \%$ in men and women, respectively. Information about characteristics of study subjects across tertiles of total BCAAs intake as well as by categories of valine, leucine, and isoleucine intake are shown in Table 1. Compared with those with the lowest intake, participants with the highest consumption of total BCAAs as well as individuals' amino acids of valine, leucine, and isoleucine were more likely to be older and physically active and less likely to be female and own a home. Furthermore, individuals in the top tertile of leucine intake were less likely to be current smoker. No other significant differences were found in terms of other variables.

Dietary intakes of study participants across tertiles of total BCAAs are shown in Table 2. Compared with those in the lowest tertile of total BCAAs intake, participants in the highest tertile of total BCAAs intake had significantly higher intakes of energy, fat, protein, calcium, and vitamin D and lower intakes of carbohydrate, dietary fiber, fructose, folate, and caffeine.

Dietary intakes of study participants across tertiles of valine, leucine, and isoleucine are shown in Table 3. Individuals in the highest tertile of valine, leucine, and isoleucine intake had greater intakes of energy, fat, protein, calcium, and vitamin D and lower intakes of carbohydrate, dietary fiber, fructose, folate, and caffeine compared with those in the lowest tertile.

Crude and multivariable-adjusted odds ratios (ORs) and 95\% confidence intervals (Cls) for general and abdominal obesity across tertiles of total BCAAs are shown in Table 4. After controlling for potential confounders, we found that participants in the top tertile of total BCAAs intake had higher odds of general obesity compared with those in the bottom tertile (OR: 1.42; $95 \% \mathrm{Cl}$ : 1.09-1.84), such that those in the highest tertile of BCAAs intake had $42 \%$ higher odds of general obesity. When we did the analysis stratified by sex, we found a significant positive association between total BCAAs intake and odds of general obesity in men (OR: 1.57; 95\% Cl: 1.05-2.34), but not in women (OR: 1.33; 95\% Cl: 0.94-1.89). We found no significant association between total BCAAs intake and odds of abdominal obesity neither in crude (OR: 1.03; 95\% Cl: 0.88-1.20), nor in adjusted model (OR: 1.09; 95\% Cl: 0.88-1.34). In addition, these associations were not significant in men (OR: 1.10; $95 \% \mathrm{Cl}$ : 0.74-1.65) and women (OR: 1.08; 95\% Cl: 0.84-1.38).

Crude and multivariable-adjusted ORs and $95 \% \mathrm{Cls}$ for general and abdominal obesity across tertiles of valine, leucine, and isoleucine are shown in Table 5 . In the fully adjusted model, those in the highest tertile of valine intake had higher chance for general obesity (OR: 1.42; 95\% Cl: 1.10-1.84) compared with those in the lowest tertiles. The same associations were reached for leucine (OR: 1.43; 95\% Cl: 1.10-1.86) and isoleucine intake (OR: 1.42; 95\% Cl: 1.09-1.84). Stratified by sex, we found that valine, leucine, and isoleucine intake was significantly associated with odds of general obesity in men [for valine: (OR: 1.54; $95 \%$ Cl: $1.03-$ 2.29), for leucine: (OR: 1.59; 95\% Cl: 1.07-2.37), and for isoleucine: (OR:1.51; 95\% Cl: 1.01-2.25)], but not in women. With regard to abdominal obesity, we observed no significant association between valine, leucine, and isoleucine intake and odds of abdominal obesity, either before or after adjustment for 
potential confounders. In addition, there was no significant association between valine, leucine, and isoleucine intake and odds of abdominal obesity by gender.

\section{Discussion}

In this cross-sectional study, we found a positive association between total BCAAs, leucine, isoleucine, and valine intake and odds of general obesity. Such association was found in men, but not in women. There was no significant association between total and individual BCAAs intake and abdominal obesity. Increase consumption of dietary BCAAs result in increased plasma levels of BCAAs. Earlier studies have found a positive association between plasma levels of BCAAs and visceral adipose tissue (VAT) and insulin resistance $(8,9)$. A cross-sectional study in China reported that children of mothers with GDM who had higher intake of BCAAs had higher odds of overweight and insulin resistance (11). In addition, in an experimental study, restriction of dietary BCAAs resulted in weight loss and improved glucose tolerance and insulin sensitivity in diet-induced obese mice (21). On the other hand, some publications reported the beneficial effects of decreased consumption of BCAAs on metabolic health in humans $(22,23)$. In contrast to our findings, a cross-sectional study revealed a significant inverse association between dietary BCAAs and prevalence of overweight or obesity (13). Another cross-sectional study demonstrated that obese subjects, compared with non-obese individuals, had lower intakes of dietary BCAAs (24). In a recent meta-analysis, a contra-positive correlation between BCAAs intake and risk of obesity was found (10). Different findings might be explained by methodological discrepancies across studies including difference in target population, dietary assessment tools, and controlling for confounding factors in the analyses. In addition, different sample size along with nature of study design can also provide some other explanations.

We found no significant association between dietary total and individual BCAAs intake and odds of abdominal obesity. Contrary to our results, Li et al. showed that higher BCAAs intake was associated with a decreased odds of abdominal obesity (24). In addition, a clinical trial revealed that subjects who consume a hypocaloric diet high in BCAAs had greater weight loss and lower percentage of body fat and abdominal obesity than those in hypocaloric control, hypocaloric high-protein, hypocaloric low-protein, and control diet groups (25). Some studies have shown higher circulating levels of leucine, isoleucine, and valine among subjects with central obesity compared with peripheral obesity (26). One possible explanation for lack of a significant relationship in the current study might be the definition of central obesity. We used the criteria suggested for Western countries $(27,28)$, while this definition and the cut-off points used might be different in Middle Eastern countries like Iran. In addition, we assessed abdominal obesity based on WC only. Others have used waist-to-hip and waist-toheight ratios for this definition (29-31). Additionally, we evaluated all anthropometric measures, including WC, through self-reported data. Although a significant association was seen between self-reported and actually measured data in our validation study, the correlation was not as strong as for weight and height. Therefore, some sort of misclassification of participants in terms of abdominal obesity might have occurred.

There are several potential mechanisms through which BCAAs might influence body weight. BCAAs might stimulate secretion of both insulin and glucagon and, when administered orally, result in increased prolonged insulin and glucagon secretion (32). The role of insulin in the pathogenesis of obesity and excess adiposity has been previously proposed $(33,34)$. On the other hand, insulin can increase the uptake of amino acids such as BCAAs and facilitate the protein synthesis in the body $(35,36)$. As a result, this leads to increased skeletal muscle weight and eventually body weight $(37)$. Furthermore, some studies indicated that insulin activity is impaired by BCAAs supplementation, which can in turn increase the activity of mammalian target of rapamycin (mTOR) (38, 39). Moreover, 3-hydroxy-isobutyrate (3-HIB), a metabolite of valine, activates uptake of fatty acids to the muscle, which can result in accumulated body fat in animals (7). It is demonstrated that the changes in this metabolite were correlated with metabolic improvements with weight loss in humans (40). In our study, we found a significant positive association between BCAAs intake and general obesity in men, but not in women. The reasons of this gender discrepancy are unknown, but it has been suggested that BCAAs can boost testosterone secretion (41) and, therefore, increase lean body mass (42), which might have been resulted in a greater weight in men.

The present study has some strengths including large sample size and controlling for a wide range of potential confounders in the analyses. However, some limitations must be considered. First, this study has cross-sectional design that would not allow to infer causal relationship between dietary BCAAs and obesity. Therefore, further studies are needed in this regard to confirm our findings. Second, despite for adjusting for several variables in the study, the role of residual confounding cannot be excluded. Third, although we used a validated FFQ for assessment of dietary intakes, some degree of measurement error and misclassification is unavoidable. Finally, we used self-reported data of anthropometric measures in the current study, which can further bring some sort of bias into our findings.

In conclusion, we found a significant positive association between dietary BCAAs and general obesity in the whole population. Such association was found in men, but not in women. Dietary BCAAs was not associated with abdominal obesity.

\section{What is already known on this subject?}

Several studies found that higher circulating BCAAs were associated with increased risk of obesity-related conditions such as metabolic disorders and type 2 diabetes. BCAAs and their metabolites can result in insulin resistance and impaired glucose tolerance and eventually increased visceral fat accumulation and obesity. Some studies have revealed that dietary intake of BCAAs was associated with increased circulating levels of these amino acids, but other studies had the opposite findings.

\section{What does this study add?}

Given the controversial findings with regard to the association between dietary BCAA intake and obesity, and increasing prevalence of obesity in MiddleEastern countries, we decided to conduct the present study. We found a positive association between dietary BCAA intake and obesity among adults. By gender, such association was found in men, but not in women. Dietary BCAAs was not associated with abdominal obesity.

\section{Declarations}


Acknowledgements: The authors are thankful to participants of SEPAHAN project and authorities of Isfahan University of Medical Sciences for their excellent cooperation.

Author contributions: FA, ASM, and AE contributed to the conception and design of the study, data collection, statistical analysis, and drafting of the manuscript; AHK and PA contributed to the conception and design of the study, data collection, and manuscript drafting. All authors read and approved the final manuscript.

\section{Compliance with Ethical Standards}

Conflict of interest: None of the authors declared any conflict of interest.

Funding: No funding was received for conducting this study.

Ethical approval: This study was approved by the Bioethics Committee of Isfahan University of Medical Sciences, Isfahan, Iran (Ethics approval number: \#189069, \#189082, and\#189086).

Informed consent: All participants provided written informed consent forms.

\section{References}

1. Shimomura Y, Kitaura Y, Kadota Y, ISHIkAWA T, Kondo Y, Xu M, et al. Novel physiological functions of branched-chain amino acids. J Nutr Sci Vitaminol. 2015;61(Supplement):S112-S4. https://doi.org/ 10.3177/jnsv.61.S112.

2. Siddik MAB, Shin AC. Recent progress on branched-chain amino acids in obesity, diabetes, and beyond. Endocrinol Metab. 2019;34(3):234-46. https://doi.org/ 10.3803/EnM.2019.34.3.234.

3. Badoud F, Lam KP, DiBattista A, Perreault M, Zulyniak MA, Cattrysse B, et al. Serum and adipose tissue amino acid homeostasis in the metabolically healthy obese. J Proteome Res. 2014;13(7):3455-66. https://doi.org/ 10.1021/pr500416v.

4. Würtz P, Soininen P, Kangas AJ, Rönnemaa T, Lehtimäki T, Kähönen M, et al. Branched-chain and aromatic amino acids are predictors of insulin resistance in young adults. Diabetes care. 2013;36(3):648-55. https://doi.org/ 10.2337/dc12-0895.

5. Yamakado M, Nagao K, Imaizumi A, Tani M, Toda A, Tanaka T, et al. Plasma free amino acid profiles predict four-year risk of developing diabetes, metabolic syndrome, dyslipidemia, and hypertension in Japanese population. Sci Rep. 2015;5:11918. https://doi.org/ 10.1038/srep11918.

6. Chen X, Yang W. Branched-chain amino acids and the association with type 2 diabetes. J Diabetes Investig. 2015;6(4):369-70. https ://doi.org/ 10.1111/jdi.12345.

7. Jang C, Oh SF, Wada S, Rowe GC, Liu L, Chan MC, et al. A branched-chain amino acid metabolite drives vascular fatty acid transport and causes insulin resistance. Nature Med. 2016;22(4):421-6. https://doi.org/ 10.1038/nm.4057.

8. Rietman A, Stanley TL, Clish C, Mootha V, Mensink M, Grinspoon SK, et al. Associations between plasma branched-chain amino acids, $\beta$-aminoisobutyric acid and body composition. J Nutr Sci. 2016;5. https://doi.org/ 10.1017/jns.2015.37.

9. Newgard CB, An J, Bain JR, Muehlbauer MJ, Stevens RD, Lien LF, et al. A branched-chain amino acid-related metabolic signature that differentiates obese and lean humans and contributes to insulin resistance. Cell metab. 2009;9(4):311-26. https://doi.org/ 10.1016/j.cmet.2009.02.002.

10. Okekunle AP, Zhang M, Wang Z, Onwuka JU, Wu X, Feng R, et al. Dietary branched-chain amino acids intake exhibited a different relationship with type 2 diabetes and obesity risk: A meta-analysis. Acta Diabetol. 2019;56(2):187-95. https://doi.org/ 10.1007/s00592-018-1243-7.

11. Lu J, Gu Y, Liu H, Wang L, Li W, Li W, et al. Daily Branched-Chain Amino Acid Intake and Risks of Obesity and Insulin Resistance in Children: A CrossSectional Study. Obesity. 2020. https://doi.org/ 10.1002/oby.22834.

12. Martin F-PJ, Montoliu I, Collino S, Scherer M, Guy P, Tavazzi I, et al. Topographical body fat distribution links to amino acid and lipid metabolism in healthy non-obese women. PloS One. 2013;8(9):e73445. https://doi.org/ 10.1371/journal.pone.0073445.

13. Qin LQ, Xun P, Bujnowski D, Daviglus ML, Van Horn L, Stamler J, et al. Higher branched-chain amino acid intake is associated with a lower prevalence of being overweight or obese in middle-aged East Asian and Western adults. J Nutr. 2011;141(2):249-54. https://doi.org/ 10.3945/jn.110.128520.

14. Adibi P, Keshteli AH, Esmaillzadeh A, Afshar H, Roohafza H, Bagherian-Sararoudi R, et al. The study on the epidemiology of psychological, alimentary health and nutrition (SEPAHAN): overview of methodology. J Res Med Sci. 2012;17(5):S292-S8.

15. Willett W. Nutritional epidemiology: Oxford university press; 2012.

16. Keshteli AH, Esmaillzadeh A, Rajaie S, Askari G, Feinle-Bisset C, Adibi P. A dish-based semi-quantitative food frequency questionnaire for assessment of dietary intakes in epidemiologic studies in Iran: design and development. Int J Prev Med. 2014;5(1):29.

17. Ghaffarpour M, Houshiar-Rad A, Kianfar H. The manual for household measures, cooking yields factors and edible portion of foods. Tehran: Nashre Olume Keshavarzy. 1999;7:213.

18. Kimura Y, Wada T, Okumiya K, Ishimoto Y, Fukutomi E, Kasahara Y, et al. Eating alone among community-dwelling Japanese elderly: association with depression and food diversity. J Nutr Health Aging. 2012;16(8):728-31. https://doi.org/ 10.1007/s12603-012-0067-3.

19. Third Report of the National Cholesterol Education Program (NCEP) Expert Panel on Detection, Evaluation, and Treatment of High Blood Cholesterol in Adults (Adult Treatment Panel III) final report. Circulation. 2002;106(25):3143-421.

20. Department of Health. The general practice physical activity questionnaire. Department of Health, London 2009. 
21. Cummings NE, Williams EM, Kasza I, Konon EN, Schaid MD, Schmidt BA, et al. Restoration of metabolic health by decreased consumption of branchedchain amino acids. J Physiol. 2018;596(4):623-45. https://doi.org/ 10.1113/JP275075.

22. Fontana L, Cummings NE, Apelo SIA, Neuman JC, Kasza I, Schmidt BA, et al. Decreased consumption of branched-chain amino acids improves metabolic health. Cell rep. 2016;16(2):520-30. https://doi.org/ 10.1016/j.celrep.2016.05.092.

23. Hill CM, Morrison CD. Dietary branched chain amino acids and metabolic health: when less is more. J Physiol. 2018;596(4):555. https://doi.org/ $10.1113 / J P 275613$.

24. Li Y-C, Li Y, Liu L-Y, Chen Y, Zi T-Q, Du S-S, et al. The ratio of dietary branched-chain amino acids is associated with a lower prevalence of obesity in young northern Chinese adults: An internet-based cross-sectional study. Nutrients. 2015;7(11):9573-89. https://doi.org/ 10.3390/nu7115486.

25. Mourier A, Bigard A, de Kerviler E, Roger B, Legrand H, Guezennec C. Combined effects of caloric restriction and branched-chain amino acid supplementation on body composition and exercise performance in elite wrestlers. Int J Sports Med. 1997;18(01):47-55. https://doi.org/ 10.1055/s-2007972594.

26. Gao X, Zhang W, Wang Y, Pedram P, Cahill F, Zhai G, et al. Serum metabolic biomarkers distinguish metabolically healthy peripherally obese from unhealthy centrally obese individuals. Nutr Metab. 2016;13(1):33. https://doi.org/ 10.1186/s12986-016-0095-9.

27. Detection NCEPEPo, Adults ToHBCi. Third report of the National Cholesterol Education Program (NCEP) Expert Panel on detection, evaluation, and treatment of high blood cholesterol in adults (Adult Treatment Panel III): National Cholesterol Education Program, National Heart, Lung, and Blood ...; 2002.

28. Lean ME, Han TS, Morrison CE. Waist circumference as a measure for indicating need for weight management. BMJ. 1995;311(6998):158-61. https://doi.org/ 10.1136/bmj.311.6998.158.

29. Jia W-P, Lu J-X, Xiang K-S, Bao Y-Q, Lu H-J, Chen L. Prediction of abdominal visceral obesity from body mass index, waist circumference and waist-hip ratio in Chinese adults: receiver operating characteristic curves analysis. Biomed Environ Sci: BES. 2003;16(3):206-11.

30. Rankinen T, Kim S, Perusse L, Despres J, Bouchard C. The prediction of abdominal visceral fat level from body composition and anthropometry: ROC analysis. Int J Obes. 1999;23(8):801-9. https://doi.org/ 10.1038/sj.ijo.0800929.

31. Wu H-y, Xu S-y, Chen L-I, Zhang H-f. Waist to height ratio as a predictor of abdominal fat distribution in men. Chin J Physiol. 2009;52(6):441-5. https://doi.org/ 10.4077/cjp.2009.amh064.

32. Gojda J, Straková R, Plíhalová A, Tůma P, Potočková J, Polák J, et al. Increased Incretin But Not Insulin Response after Oral versus Intravenous Branched Chain Amino Acids. Ann Nutr Metab. 2017;70(4):293-302. https://doi.org/ 10.1159/000475604.

33. Sigal RJ, El-Hashimy M, Martin BC, Soeldner JS, Krolewski AS, Warram JH. Acute postchallenge hyperinsulinemia predicts weight gain: a prospective study. Diabetes. 1997;46(6):1025-9. https://doi.org/ 10.2337/diab.46.6.1025.

34. van Vliet S, Koh H-CE, Patterson BW, Yoshino M, LaForest R, Gropler RJ, et al. Obesity is associated with increased basal and postprandial $\beta$-cell insulin secretion even in the absence of insulin resistance. Diabetes. 2020;69(10):2112-9. https ://doi.org/ 10.2337/db20-0377.

35. Fukagawa NK, Minaker KL, Rowe JW, Goodman MN, Matthews DE, Bier DM, et al. Insulin-mediated reduction of whole body protein breakdown. Doseresponse effects on leucine metabolism in postabsorptive men. J Clin Invest. 1985;76(6):2306-11. https://doi.org/ 10.1172/JCl112240.

36. Tessari P. Effects of insulin on whole-body and regional amino acid metabolism. Diabetes/metabolism reviews. 1994;10(3):253-85. https://doi.org/ 10.1002/dmr.5610100304.

37. Fujita S, Rasmussen BB, Cadenas JG, Grady JJ, Volpi E. Effect of insulin on human skeletal muscle protein synthesis is modulated by insulin-induced changes in muscle blood flow and amino acid availability. Am J Physiol Endocrinol Metab. 2006;291(4):E745-E54. https://doi.org/ 10.1152/ajpendo.00271.2005

38. Tremblay F, Krebs M, Dombrowski L, Brehm A, Bernroider E, Roth E, et al. Overactivation of S6 kinase 1 as a cause of human insulin resistance during increased amino acid availability. Diabetes. 2005;54(9):2674-84. https://doi.org/ 10.2337/diabetes.54.9.2674.

39. Tzatsos A, Kandror KV. Nutrients suppress phosphatidylinositol 3-kinase/Akt signaling via raptor-dependent mTOR-mediated insulin receptor substrate 1 phosphorylation. Mol Cell Biol. 2006;26(1):63-76. https://doi.org/ 10.1128/MCB.26.1.63-76.2006.

40. Haufe S, Engeli S, Kaminski J, Witt H, Rein D, Kamlage B, et al. Branched-chain amino acid catabolism rather than amino acids plasma concentrations is associated with diet-induced changes in insulin resistance in overweight to obese individuals. Nutr Metab Cardiovasc Dis: NMCD. 2017;27(10):858-64. https://doi.org/ 10.1016/j.numecd.2017.07.001.

41. Hsu M-C, Chien K-Y, Hsu C-C, Chung C-J, Chan K-H, Su B. Effects of BCAA, arginine and carbohydrate combined drink on post-exercise biochemical response and psychological condition. Chin J Physiol. 2011;54(2):71-8. https://doi.org/ 10.4077/cjp.2011.amk075.

42. Herbst KL, Bhasin S. Testosterone action on skeletal muscle. Curr Opin Clin Nutr Metab Care. 2004;7(3):271-7. https://doi.org/ 10.1097/00075197200405000-00006.

\section{Tables}




\begin{tabular}{|c|c|c|c|c|c|c|c|c|c|c|c|c|}
\hline & \multicolumn{2}{|c|}{ Total BCAAs } & \multirow{2}{*}{$\begin{array}{l}\text { P- } \\
\text { value }^{a}\end{array}$} & \multicolumn{2}{|l|}{ Valine } & \multirow{2}{*}{$\begin{array}{l}\text { P- } \\
\text { value }^{a}\end{array}$} & \multicolumn{2}{|l|}{ Leucine } & \multirow{2}{*}{$\begin{array}{l}\text { P- } \\
\text { value }^{a}\end{array}$} & \multicolumn{2}{|l|}{ Isoleucine } & \multirow{2}{*}{$\begin{array}{l}\text { P- } \\
\text { value }^{a}\end{array}$} \\
\hline & $\mathrm{T}_{1}$ & $\mathrm{~T}_{3}$ & & $\mathrm{~T}_{1}$ & $\mathrm{~T}_{3}$ & & $\mathrm{~T}_{1}$ & $\mathrm{~T}_{3}$ & & $\mathrm{~T}_{1}$ & $\mathrm{~T}_{3}$ & \\
\hline Age, y & $36.9 \pm 7.9$ & $37.2 \pm 8.3$ & 0.02 & $36.8 \pm 7.9$ & $37.2 \pm 8.2$ & 0.04 & $36.8 \pm 7.9$ & $37.2 \pm 8.3$ & 0.02 & $36.9 \pm 7.8$ & $37.1 \pm 8.3$ & 0.05 \\
\hline Female, \% & 59.2 & 56 & 0.006 & 59.3 & 56.4 & 0.01 & 59.1 & 55.9 & 0.002 & 58.9 & 56.3 & 0.006 \\
\hline Married, \% & 82.4 & 82.6 & 0.24 & 82.6 & 82.8 & 0.56 & 82.6 & 82.8 & 0.75 & 82.6 & 82.4 & 0.13 \\
\hline $\begin{array}{l}\text { University } \\
\text { graduated, \% }\end{array}$ & 60.5 & 59.6 & 0.79 & 60.7 & 59.5 & 0.70 & 60.4 & 59.6 & 0.77 & 59.9 & 59.9 & 0.79 \\
\hline $\begin{array}{l}\text { Family size (>4 } \\
\text { people), \% }\end{array}$ & 10.9 & 9.2 & 0.14 & 10.7 & 9.1 & 0.13 & 10.9 & 9.2 & 0.13 & 11 & 9.1 & 0.11 \\
\hline $\begin{array}{l}\text { Current smoker, } \\
\%\end{array}$ & 4.4 & 4 & 0.05 & 4.2 & 4.1 & 0.19 & 4.5 & 4 & 0.03 & 4.6 & 4 & 0.05 \\
\hline $\begin{array}{l}\text { Physically active } \\
\text { ( } \geq 1 \text { h/week), \% }\end{array}$ & 31.4 & 36.4 & 0.002 & 31.6 & 35.9 & 0.01 & 31.6 & 36.2 & 0.007 & 30.8 & 37 & $<0.001$ \\
\hline $\begin{array}{l}\text { Breakfast } \\
\text { skipping ( } \geq 4 \\
\text { times/week), \% }\end{array}$ & 76.6 & 76.9 & 0.89 & 76.4 & 77.2 & 0.73 & 76.6 & 76.7 & 0.99 & 76.6 & 76.6 & 0.98 \\
\hline $\begin{array}{l}\text { Home ownership } \\
\text { (non-owner), \% }\end{array}$ & 34.3 & 29.9 & 0.01 & 34.4 & 29.2 & 0.003 & 34.6 & 29.8 & 0.004 & 34.4 & 29.8 & 0.007 \\
\hline
\end{tabular}

All values are mean $\pm S D$, unless indicated

aANOVA for continuous variables and chi-squared test for categorical variables

Table 2: Dietary intakes of study participants across tertiles of total BCAAs intake

\begin{tabular}{|c|c|c|c|c|}
\hline & \multicolumn{4}{|c|}{ Tertiles of total BCAAs } \\
\hline & $\mathrm{T}_{1}$ & $\mathrm{~T}_{2}$ & $\mathrm{~T}_{3}$ & P-value ${ }^{a}$ \\
\hline Energy $(\mathrm{kcal} / \mathrm{d})$ & $2486.3 \pm 853.6$ & $2116.7 \pm 790.4$ & $2511.9 \pm 796.6$ & $<0.001$ \\
\hline Fat (g/day) & $95.2 \pm 36.2$ & $90.4 \pm 35.5$ & $111.8 \pm 38.2$ & $<0.001$ \\
\hline Protein (g/day) & $82.2 \pm 31.5$ & $77.3 \pm 28.8$ & $105.7 \pm 34.4$ & $<0.001$ \\
\hline Carbohydrate (g/day) & $333.7 \pm 125.3$ & $256.6 \pm 105.6$ & $279.6 \pm 103.4$ & $<0.001$ \\
\hline Dietary fiber (g/day) & $24.1 \pm 9.6$ & $20.3 \pm 9.3$ & $22.9 \pm 9.9$ & $<0.001$ \\
\hline Fructose (g/day) & $19.8 \pm 13.5$ & $15.02 \pm 11.2$ & $15.8 \pm 10.6$ & $<0.001$ \\
\hline Calcium (mg/day) & $970.5 \pm 616.3$ & $786.9 \pm 398.1$ & $1098.8 \pm 504.7$ & $<0.001$ \\
\hline Vitamin D ( $\mu \mathrm{g} /$ day $)$ & $31.2 \pm 21.3$ & $35.3 \pm 25.4$ & $43.8 \pm 27.6$ & $<0.001$ \\
\hline Folate $(\mu \mathrm{g} /$ day $)$ & $627.2 \pm 264.8$ & $501.2 \pm 203.6$ & $560.9 \pm 211.8$ & $<0.001$ \\
\hline Caffeine (mg/day) & $120.5 \pm 119.7$ & $89.8 \pm 75.7$ & $89.2 \pm 76.7$ & $<0.001$ \\
\hline
\end{tabular}

Data are mean \pm standard deviation (SD)

a Obtained from ANOVA 


\begin{tabular}{|c|c|c|c|c|c|c|c|c|c|}
\hline & \multicolumn{2}{|l|}{ Valine } & \multirow[t]{2}{*}{ P-value ${ }^{a}$} & \multicolumn{2}{|l|}{ Leucine } & \multirow[t]{2}{*}{$P$-value ${ }^{a}$} & \multicolumn{2}{|l|}{ Isoleucine } & \multirow[t]{2}{*}{$P-$} \\
\hline & $\mathrm{T}_{1}$ & $\mathrm{~T}_{3}$ & & $\mathrm{~T}_{1}$ & $\mathrm{~T}_{3}$ & & $\mathrm{~T}_{1}$ & $\mathrm{~T}_{3}$ & \\
\hline $\begin{array}{l}\text { Energy } \\
(\text { kcal/d) }\end{array}$ & $2474.7 \pm 857$ & $2515.7 \pm 794$ & $<0.001$ & $2484.5 \pm 849.9$ & $2515.5 \pm 796.5$ & $<0.001$ & $2504 \pm 844.7$ & $2503.7 \pm 797.6$ & $<0.1$ \\
\hline Fat (g/day) & $94.9 \pm 36.3$ & $111.8 \pm 38.1$ & $<0.001$ & $95.3 \pm 36.1$ & $111.9 \pm 38.2$ & $<0.001$ & $95.7 \pm 35.8$ & $111.7 \pm 38.2$ & $<0.1$ \\
\hline $\begin{array}{l}\text { Protein } \\
\text { (g/day) }\end{array}$ & $82.07 \pm 31.5$ & $105.4 \pm 34.4$ & $<0.001$ & $82.2 \pm 31.4$ & $105.8 \pm 34.3$ & $<0.001$ & $82.5 \pm 31.1$ & $105.6 \pm 34.3$ & $<0.1$ \\
\hline $\begin{array}{l}\text { Carbohydrate } \\
\text { (g/day) }\end{array}$ & $331.6 \pm 125.8$ & $280.9 \pm 103.6$ & $<0.001$ & $333.1 \pm 124.8$ & $280.2 \pm 103.8$ & $<0.001$ & $336.7 \pm 124.5$ & $277.7 \pm 103$ & $<0.1$ \\
\hline $\begin{array}{l}\text { Dietary fiber } \\
\text { (g/day) }\end{array}$ & $24.1 \pm 9.6$ & $22.9 \pm 9.9$ & $<0.001$ & $24.1 \pm 9.5$ & $23.1 \pm 10.03$ & $<0.001$ & $24.3 \pm 9.6$ & $22.8 \pm 9.8$ & $<0.1$ \\
\hline $\begin{array}{l}\text { Fructose } \\
\text { (g/day) }\end{array}$ & $19.6 \pm 13.5$ & $15.9 \pm 10.7$ & $<0.001$ & $19.8 \pm 13.5$ & $15.8 \pm 10.5$ & $<0.001$ & $19.7 \pm 13.6$ & $15.8 \pm 10.6$ & $<0.1$ \\
\hline $\begin{array}{l}\text { Calcium } \\
\text { (mg/day) }\end{array}$ & $957.2 \pm 613.8$ & $1115.1 \pm 501.4$ & $<0.001$ & $971.06 \pm 616$ & $1096.4 \pm 502.8$ & $<0.001$ & $987.6 \pm 614.9$ & $1077.9 \pm 507.6$ & $<0.1$ \\
\hline $\begin{array}{l}\text { Vitamin D } \\
(\mu \mathrm{g} / \text { day })\end{array}$ & $30.6 \pm 21.1$ & $44.5 \pm 29.7$ & $<0.001$ & $31.4 \pm 21.4$ & $43.6 \pm 27.5$ & $<0.001$ & $31.6 \pm 21.5$ & $43.3 \pm 27.6$ & $<0.1$ \\
\hline $\begin{array}{l}\text { Folate } \\
\text { ( } \mu \mathrm{g} / \text { day) }\end{array}$ & $624.4 \pm 265.5$ & $562.9 \pm 212.2$ & $<0.001$ & $626.03 \pm 264.1$ & $563.04 \pm 212.6$ & $<0.001$ & $633.8 \pm 264.4$ & $556.9 \pm 209.5$ & $<0.1$ \\
\hline $\begin{array}{l}\text { Caffeine } \\
\text { (mg/day) }\end{array}$ & $119.2 \pm 119.5$ & $88.4 \pm 75.2$ & $<0.001$ & $119.9 \pm 119.8$ & $89.01 \pm 75.8$ & $<0.001$ & $120.7 \pm 119.2$ & $88.8 \pm 77.5$ & $<0.1$ \\
\hline
\end{tabular}

Data are mean \pm standard deviation (SD)

${ }^{a}$ Obtained from ANOVA

Table 4: Crude and multivariable-adjusted ORs and $95 \% \mathrm{Cls}$ for general and abdominal obesity across tertiles of total BCAAs intake 


\begin{tabular}{|c|c|c|c|c|}
\hline & \multicolumn{4}{|c|}{ Tertiles of total BCAAs } \\
\hline & $\begin{array}{l}\mathrm{T}_{1} \\
(\mathrm{n}=2241)\end{array}$ & $\begin{array}{l}T_{2} \\
(n=2242)\end{array}$ & $\begin{array}{l}T_{3} \\
(n=2241)\end{array}$ & P-trend \\
\hline \multicolumn{5}{|c|}{ General obesity } \\
\hline \multicolumn{5}{|c|}{ Whole population } \\
\hline Crude & 1.00 & $1.15(0.94-1.41)$ & $1.21(0.99-1.48)$ & 0.06 \\
\hline Model la & 1.00 & $1.10(0.89-1.35)$ & $1.21(0.99-1.48)$ & 0.06 \\
\hline Model II & 1.00 & $1.19(0.91-1.56)$ & $1.37(1.05-1.77)$ & 0.01 \\
\hline Model III & 1.00 & $1.21(0.93-1.58)$ & $1.42(1.09-1.84)$ & 0.008 \\
\hline \multicolumn{5}{|l|}{ Men } \\
\hline Crude & 1.00 & $1.22(0.87-1.73)$ & $1.38(1.00-1.92)$ & 0.05 \\
\hline Model $\mathrm{I}^{\mathrm{b}}$ & 1.00 & $1.16(0.82-1.65)$ & $1.39(1.00-1.92)$ & 0.04 \\
\hline Model II & 1.00 & $1.31(0.85-2.02)$ & $1.52(1.02-2.27)$ & 0.03 \\
\hline Model III & 1.00 & $1.31(0.86-2.02)$ & $1.57(1.05-2.34)$ & 0.02 \\
\hline \multicolumn{5}{|l|}{ Women } \\
\hline Crude & 1.00 & $1.08(0.83-1.39)$ & $1.08(0.83-1.40)$ & 0.55 \\
\hline Model I & 1.00 & $1.04(0.81-1.35)$ & $1.08(0.83-1.41)$ & 0.53 \\
\hline Model II & 1.00 & $1.11(0.78-1.57)$ & $1.28(0.90-1.81)$ & 0.15 \\
\hline Model III & 1.00 & $1.13(0.80-1.60)$ & $1.33(0.94-1.89)$ & 0.10 \\
\hline \multicolumn{5}{|c|}{ Abdominal obesity } \\
\hline \multicolumn{5}{|c|}{ Whole population } \\
\hline Crude & 1.00 & $1.12(0.97-1.31)$ & $1.03(0.88-1.20)$ & 0.70 \\
\hline Model la & 1.00 & $1.07(0.92-1.26)$ & $1.06(0.91-1.25)$ & 0.41 \\
\hline Model II & 1.00 & $1.16(0.94-1.42)$ & $1.07(0.86-1.31)$ & 0.51 \\
\hline Model III & 1.00 & $1.17(0.95-1.43)$ & $1.09(0.88-1.34)$ & 0.38 \\
\hline \multicolumn{5}{|l|}{ Men } \\
\hline Crude & 1.00 & $1.01(0.73-1.40)$ & $1.00(0.73-1.37)$ & 0.99 \\
\hline Model Ib & 1.00 & $1.00(0.72-1.40)$ & $1.00(0.73-1.37)$ & 0.99 \\
\hline Model II & 1.00 & $1.27(0.85-1.92)$ & $1.08(0.73-1.62)$ & 0.69 \\
\hline Model III & 1.00 & $1.27(0.84-1.91)$ & $1.10(0.74-1.65)$ & 0.62 \\
\hline \multicolumn{5}{|l|}{ Women } \\
\hline Crude & 1.00 & $1.13(0.95-1.35)$ & $1.08(0.90-1.30)$ & 0.36 \\
\hline Model $\mathrm{I}^{\mathrm{b}}$ & 1.00 & $1.10(0.92-1.31)$ & $1.08(0.90-1.30)$ & 0.35 \\
\hline Model II & 1.00 & $1.12(0.88-1.42)$ & $1.05(0.82-1.35)$ & 0.63 \\
\hline Model III & 1.00 & $1.13(0.89-1.44)$ & $1.08(0.84-1.38)$ & 0.49 \\
\hline
\end{tabular}

Data are OR $(95 \% \mathrm{Cl})$

Model I $\mathrm{I}^{\mathrm{a}}$ : adjusted for age, sex, and energy intake

Model I $\mathrm{I}^{\mathrm{b}}$ : adjusted for age and energy intake

Model II: additionally, adjusted for marital status, education, family size, smoking status, physical activity, breakfast skipping, and home ownership Model III: additionally, adjusted for dietary fiber intake 


\begin{tabular}{|c|c|c|c|c|c|c|c|c|c|}
\hline & \multicolumn{2}{|c|}{ Valine } & \multirow[t]{2}{*}{ P-trend } & \multicolumn{2}{|c|}{ Leucine } & \multirow[t]{2}{*}{ P-trend } & \multicolumn{2}{|c|}{ Isoleucine } & \multirow[t]{2}{*}{ P-trend } \\
\hline & $\mathrm{T}_{1}$ & $\mathrm{~T}_{3}$ & & $\mathrm{~T}_{1}$ & $\mathrm{~T}_{3}$ & & $\mathrm{~T}_{1}$ & $\mathrm{~T}_{3}$ & \\
\hline \multicolumn{10}{|c|}{ General obesity } \\
\hline \multicolumn{10}{|c|}{ Whole population } \\
\hline Crude & 1.00 & $1.20(0.99-1.47)$ & 0.06 & 1.00 & $1.23(1.01-1.51)$ & 0.03 & 1.00 & $1.26(1.03-1.54)$ & 0.02 \\
\hline Model la & 1.00 & $1.21(0.99-1.48)$ & 0.05 & 1.00 & $1.23(1.01-1.51)$ & 0.03 & 1.00 & $1.25(1.03-1.54)$ & 0.02 \\
\hline Model II & 1.00 & $1.37(1.06-1.76)$ & 0.01 & 1.00 & $1.38(1.07-1.79)$ & 0.01 & 1.00 & $1.36(1.05-1.77)$ & 0.01 \\
\hline Model III & 1.00 & $1.42(1.10-1.84)$ & 0.007 & 1.00 & $1.43(1.10-1.86)$ & 0.006 & 1.00 & $1.42(1.09-1.84)$ & 0.008 \\
\hline \multicolumn{10}{|l|}{ Men } \\
\hline Crude & 1.00 & $1.39(1.00-1.92)$ & 0.04 & 1.00 & $1.42(1.02-1.97)$ & 0.03 & 1.00 & $1.36(0.99-1.89)$ & 0.05 \\
\hline Model I & 1.00 & $1.39(1.01-1.93)$ & 0.03 & 1.00 & $1.43(1.03-1.98)$ & 0.03 & 1.00 & $1.37(0.99-1.89)$ & 0.05 \\
\hline Model II & 1.00 & $1.49(1.00-2.22)$ & 0.04 & 1.00 & $1.55(1.04-2.31)$ & 0.02 & 1.00 & $1.46(0.98-2.17)$ & 0.05 \\
\hline Model III & 1.00 & $1.54(1.03-2.29)$ & 0.03 & 1.00 & $1.59(1.07-2.37)$ & 0.02 & 1.00 & $1.51(1.01-2.25)$ & 0.04 \\
\hline \multicolumn{10}{|l|}{ Women } \\
\hline Crude & 1.00 & $1.08(0.83-1.40)$ & 0.53 & 1.00 & $1.09(0.84-1.41)$ & 0.51 & 1.00 & $1.16(0.89-1.50)$ & 0.27 \\
\hline Model Ib & 1.00 & $1.09(0.84-1.41)$ & 0.50 & 1.00 & $1.09(0.84-1.42)$ & 0.49 & 1.00 & $1.16(0.89-1.51)$ & 0.27 \\
\hline Model II & 1.00 & $1.28(0.91-1.80)$ & 0.14 & 1.00 & $1.27(0.90-1.80)$ & 0.17 & 1.00 & $1.31(0.92-1.85)$ & 0.12 \\
\hline Model III & 1.00 & $1.34(0.95-1.89)$ & 0.09 & 1.00 & $1.32(0.93-1.87)$ & 0.11 & 1.00 & $1.36(0.95-1.93)$ & 0.08 \\
\hline \multicolumn{10}{|c|}{ Abdominal obesity } \\
\hline \multicolumn{10}{|c|}{ Whole population } \\
\hline Crude & 1.00 & $1.04(0.89-1.21)$ & 0.56 & 1.00 & $1.04(0.89-1.21)$ & 0.57 & 1.00 & $1.00(0.86-1.16)$ & 0.99 \\
\hline Model I ${ }^{\mathrm{a}}$ & 1.00 & $1.07(0.92-1.26)$ & 0.34 & 1.00 & $1.08(0.92-1.26)$ & 0.32 & 1.00 & $1.01(0.86-1.18)$ & 0.84 \\
\hline Model II & 1.00 & $1.09(0.88-1.34)$ & 0.39 & 1.00 & $1.11(0.90-1.37)$ & 0.29 & 1.00 & $1.03(0.83-1.27)$ & 0.74 \\
\hline Model III & 1.00 & $1.12(0.91-1.38)$ & 0.27 & 1.00 & $1.14(0.92-1.40)$ & 0.20 & 1.00 & $1.05(0.85-1.30)$ & 0.58 \\
\hline \multicolumn{10}{|l|}{ Men } \\
\hline Crude & 1.00 & $0.96(0.70-1.32)$ & 0.84 & 1.00 & $0.98(0.72-1.34)$ & 0.92 & 1.00 & $0.94(0.68-1.28)$ & 0.70 \\
\hline Model Ib & 1.00 & $0.96(0.70-1.32)$ & 0.84 & 1.00 & $0.98(0.72-1.34)$ & 0.92 & 1.00 & $0.94(0.68-1.28)$ & 0.70 \\
\hline Model II & 1.00 & $1.05(0.70-1.57)$ & 0.79 & 1.00 & $1.10(0.74-1.64)$ & 0.62 & 1.00 & $1.03(0.69-1.54)$ & 0.86 \\
\hline Model III & 1.00 & $1.07(0.71-1.60)$ & 0.72 & 1.00 & $1.12(0.75-1.67)$ & 0.56 & 1.00 & $1.05(0.70-1.57)$ & 0.78 \\
\hline \multicolumn{10}{|l|}{ Women } \\
\hline Crude & 1.00 & $1.11(0.92-1.33)$ & 0.25 & 1.00 & $1.11(0.92-1.33)$ & 0.25 & 1.00 & $1.04(0.87-1.24)$ & 0.68 \\
\hline Model Ib & 1.00 & $1.11(0.93-1.33)$ & 0.23 & 1.00 & $1.11(0.93-1.33)$ & 0.24 & 1.00 & $1.04(0.86-1.24)$ & 0.66 \\
\hline Model II & 1.00 & $1.09(0.85-1.39)$ & 0.45 & 1.00 & $1.11(0.87-1.42)$ & 0.38 & 1.00 & $1.02(0.80-1.31)$ & 0.81 \\
\hline Model III & 1.00 & $1.12(0.88-1.44)$ & 0.33 & 1.00 & $1.14(0.89-1.46)$ & 0.28 & 1.00 & $1.05(0.82-1.34)$ & 0.66 \\
\hline
\end{tabular}

Data are $\mathrm{OR}(95 \% \mathrm{Cl})$

Model Ia: adjusted for age, sex, and energy intake

Model I $\mathrm{I}^{\mathrm{b}}$ : adjusted for age and energy intake

Model II: additionally, adjusted for marital status, education, family size, smoking status, physical activity, breakfast skipping, and home ownership

Model III: additionally, adjusted for dietary fiber intake

Page 10/10 